\title{
Fatores de proteção e ações de prevenção para o câncer de colo de útero: uma revisão integrativa dos últimos 10 anos
}

\author{
Protective factors and preventive actions for cervical cancer: an integrative review of the \\ past 10 years
}
Factores protectores y acciones preventivas para el cáncer cervical: uma revisión integradora de los últimos 10 años

Diana Neves Ladeia ${ }^{2 *}$, Ana Luiza Melo Lima Costa ${ }^{2}$, Ana Lívia Coelho Vieira ${ }^{1}$, Déborah Schulthais Ramos $^{2}$, Jéssica Lellis Coelho², Leiany Rodrigues de Oliveira Lima ${ }^{2}$, Luiza Penido de Freitas Santos $^{2}$, Patrícia Mendes Violante ${ }^{1}$, Pedro Miguel Vieira Bravim³ ${ }^{3}$ Adriel Gustavo Lopes ${ }^{2}$.

\section{RESUMO}

Objetivo: Realizar uma revisão integrativa acerca do tema relacionado aos fatores de proteção e ações de prevenção associadas ao câncer de colo do útero, com o intuito de levantar e compilar dados para uma melhor elucidação da eficácia dessas variáveis e o impacto na incidência da doença em questão. Métodos: Foram realizadas buscas na base de dados MEDLINE/PubMed utilizando-se os descritores "Cervical cancer; prevention; screening; cervix; pap test", "Uterine Cervical Neoplasms; cervical cancer; protective factors" e "Uterine Cervical Neoplasms; prevention; cervical cancer; protective agents", com ênfase nos últimos 10 anos. Resultados: Foram revisados os fatores de proteção e prevenção ao desenvolvimento do câncer cervical, incluindo a vacina contra os tipos carcinogênicos do vírus HPV, o exame Papanicolau, o uso de vitaminas e substâncias antioxidantes, a imunoterapia com cogumelos e o equilíbrio da microbiota vaginal. Considerações finais: Considerando a importância epidemiológica do câncer de colo de útero, é de grande relevância a busca por dados que levem à fatores protetores dessa neoplasia, além de um aprofundamento futuro nos estudos desses elementos que apresentam grande potencial de ação preventiva contra o desenvolvimento do câncer em questão.

Palavras-chave: Neoplasias do colo do útero, Prevenção, Triagem, Papanicolau, Fatores de proteção.

\begin{abstract}
Objective: Conduct a integrative review on the topic related to protective factors and prevention actions associated with cervical cancer, in order to collect and compile data for a better elucidation of the effectiveness of these variables and the impact on the incidence of the disease in question. Methods: Searches were performed in the MEDLINE/PubMed database using the descriptors "Cervical cancer; prevention; screening; cervix; pap test", "Uterine Cervical Neoplasms; cervical cancer; protective factors"and"Uterine Cervical Neoplasms; prevention; cervical cancer; protective agents", with an emphasis on the last 10 years. Results: The protective and preventive factors for the development of cervical cancer were reviewed, including the vaccine against the carcinogenic types of the HPV virus, the Pap smear, the use of vitamins and antioxidants, immunotherapy with mushrooms and the balance of the vaginal microbiota. Final considerations: Considering the epidemiological importance of cervical cancer, the search for data that lead to protective factors against this neoplasm is of great relevance, in addition to a future deepening in the studies of these elements that have great potential for preventive action against cancer development in question.
\end{abstract}

Keywords: Cervical neoplasms, Prevention, Screening, Pap smear, Protection factors.

${ }^{1}$ Faculdade da Saúde e Ecologia Humana (FASEH), Vespasiano - MG. E-mail: diananevesladeia@gmail.com 2Pontifícia Universidade Católica de Minas Gerais (PUC-MG), Betim - MG.

3Universidade de Itaúna (UIT), Itaúna - MG. 


\section{RESUMEN}

Objetivo: Realizar uma revisión integradora sobre el tema relacionado com los factores de protección y las acciones de prevención associadas com el câncer de cuello uterino, com el fin de recopilar y compilar datos para dilucidar mejor la efectividad de estas variables y el impacto em la incidência de la enfermedad em cuéston. Métodos: Se realizaron búsquedas em la base de datos MEDLINE/PubMed usando los descriptores "Cervical cancer; prevention; screening; cervix; pap test", "Uterine Cervical Neoplasms; cervical cancer; protective factors" y "Uterine Cervical Neoplasms; prevention; cervical cancer; protective agents", con énfasis en los últimos 10 años. Resultados: Se revisaron los factores de protección y prevención para el desarrollo del câncer cervical, incluida la vacuna contra los tipos cancerígenos del virus del VPH, lo examen de Papanicolau, el uso de vitaminas y sustancias antioxidantes, inmunoterapia com hongos y el equilibrio del microbiota vaginal. Consideraciones finales: Teniendo em cuenta la importancia epidemiológica del câncer de cuello uterino, la búsqueda de datos que conducen a factores protectores contra esta neoplasia es de gran relevancia, además de uma profundización futura em los estudios de estos elementos que presentan un gran potencial para la acción preventiva contra el desarrollo del câncer em cuestión.

Palabras clave: Neoplasias cervicales, Prevención, Cribado, Papanicolaou, Factores de protección.

\section{INTRODUÇÃO}

O câncer de colo de útero é, de acordo com Vonsky M, et al. (2019), o terceiro câncer mais comum no sexo feminino no mundo e a principal causa de morte de mulheres em países em desenvolvimento (RAUF A, et al., 2017). Já segundo Wang YQ, et al. (2018), o câncer cervical é o quarto câncer ginecológico mais frequente. É difundido na literatura a relação dessa neoplasia maligna com o vírus HPV (Papilomavírus humano), especialmente as cepas 16 e 18.

Apesar do HPV estar relacionado com o desenvolvimento do câncer cervical, segundo Kyrgiou M, et al. (2017), apenas a infecção pelo vírus não é suficiente para o seu desenvolvimento. Dessa forma, devemos considerar fatores de risco como tabagismo, multiparidade, imunossupressão, uso de contraceptivos hormonais orais, diversos parceiros sexuais, mulheres HIV positivo, início da atividade sexual com menos de 16 anos e histórico de verrugas vaginais como fatores que influenciam nesse processo (SILVA GA, et al., 2018; WANG YQ, et al., 2018).

Atualmente, temos a vacina quadrivalente, no Brasil, como forma de prevenção dos tipos carcinogênicos de HPV. Tal imunização, de acordo com Zhang S e Batur P (2019), pode prevenir cerca de $70 \%$ dos casos de câncer de colo do útero relacionados ao vírus, entretanto, segundo Wang $Y Q$, et al. (2018), a vacina profilática pode prevenir até $90 \%$ dos cânceres cervicais associados ao HPV.

Além disso, a realização do exame citopatológico do colo uterino é importante para o rastreamento, diagnóstico precoce e tratamento de mulheres infectadas. Devido tamanha importância epidemiológica é necessário, portanto, buscar entender os fatores de proteção do câncer cervical para explorar formas de se evitar o aparecimento da neoplasia e novos tratamentos menos tóxicos (RAUF A, et al., 2017).

Considerando que a infecção pelo HPV gera um estresse oxidativo que resulta em danos ao DNA (Ácido desoxirribonucleico) e favorece a transformação maligna de forma sinérgica, é importante o estudo de fatores antioxidantes naturais como formas de proteção e, até mesmo, para futuras estratégias terapêuticas (SILVA GA, et al., 2018). Os estudos selecionados por essa pesquisa mostraram resultados promissores no uso de diversos fatores antioxidantes como fatores de proteção do câncer cervical, assim como, também, as propriedades farmacológicas dos cogumelos.

A farmacologia dos cogumelos vem sendo estudada em busca de alvos terapêuticos para os diversos tipos de câncer do colo de útero. De acordo com Ren G, et al. (2008), a clitocina, substância produzida pelo cogumelo, tem a capacidade de inibir a capacidade proliferativa de células carcinogênicas do colo do útero através da indução apoptótica. Dentre as espécies de cogumelos com atividades antitumorais temos a Flammulina velutipes (DING Y, et al., 2009), Coprinus disseminatus (HAN B, et al., 1999), Leucopaxillus giganteus (REN G, et al., 2008) e Inonotus obliquus (ZHANG SD, et al., 2019). 
O câncer cervical invasivo ainda representa um importante problema de saúde pública (WANG YQ, et al., 2018). Sendo assim, devido à grande prevalência e incidência do câncer de colo uterino, nota-se a importância de se estudar a fundo os diversos fatores que podem estar associados à prevenção da infecção pelo HPV e difundir as informações obtidas para a população, especialmente para mulheres na idade fértil nas quais são as principais no grupo de risco. Portanto, acredita-se que variáveis como o exame preventivo, vacinação e agentes antioxidantes sejam grandes aliados na saúde da mulher.

O presente estudo tem como objetivo realizar uma revisão integrativa acerca do tema relacionado aos fatores de proteção e ações de prevenção associadas ao câncer de colo do útero, com o intuito de levantar e compilar dados para uma melhor elucidação da eficácia dessas variáveis e o impacto na incidência da doença em questão.

\section{MÉTODOS}

A base de dados Medical Literature Analisys and Retrieval System Online (MEDLINE/ PubMed) foi utilizada para fazer a busca de artigos científicos previamente publicados utilizando-se os descritores "Cervical cancer; prevention; screening; cervix; pap test", "Uterine Cervical Neoplasms; cervical cancer; protective factors" e "Uterine Cervical Neoplasms; prevention; cervical cancer; protective agents".

Os artigos foram selecionados até o ano de 2020, baseados nos seguintes critérios de inclusão: estudos de revisão científica, estudos publicados na última década (2010-2020) e estudos investigando o envolvimento de fatores protetivos para Câncer de Colo do Útero. Foram considerados critérios de exclusão: artigos originais de experimentação, estudos que foram publicados anteriormente ao ano de 2010 e estudos que não investigaram fatores protetivos para Câncer de Colo de Útero.

\section{RESULTADOS}

Os artigos incluídos na revisão foram obtidos pela estratégia de busca na base de dados MEDLINE/PubMed (Quadro 1). Inicialmente identificou-se 929 artigos, destes, 912 foram descartados por ocorrência de duplicatas, por se referirem a outras doenças, pelos dados serem insuficientes e por não abordarem os fatores protetivos do câncer do colo do útero. No estudo final foram incluídos 17 artigos para revisão (Figura 1).

Figura 1 - Diagrama representativo sobre os critérios estabelecidos para análise de inclusão e exclusão de artigos.

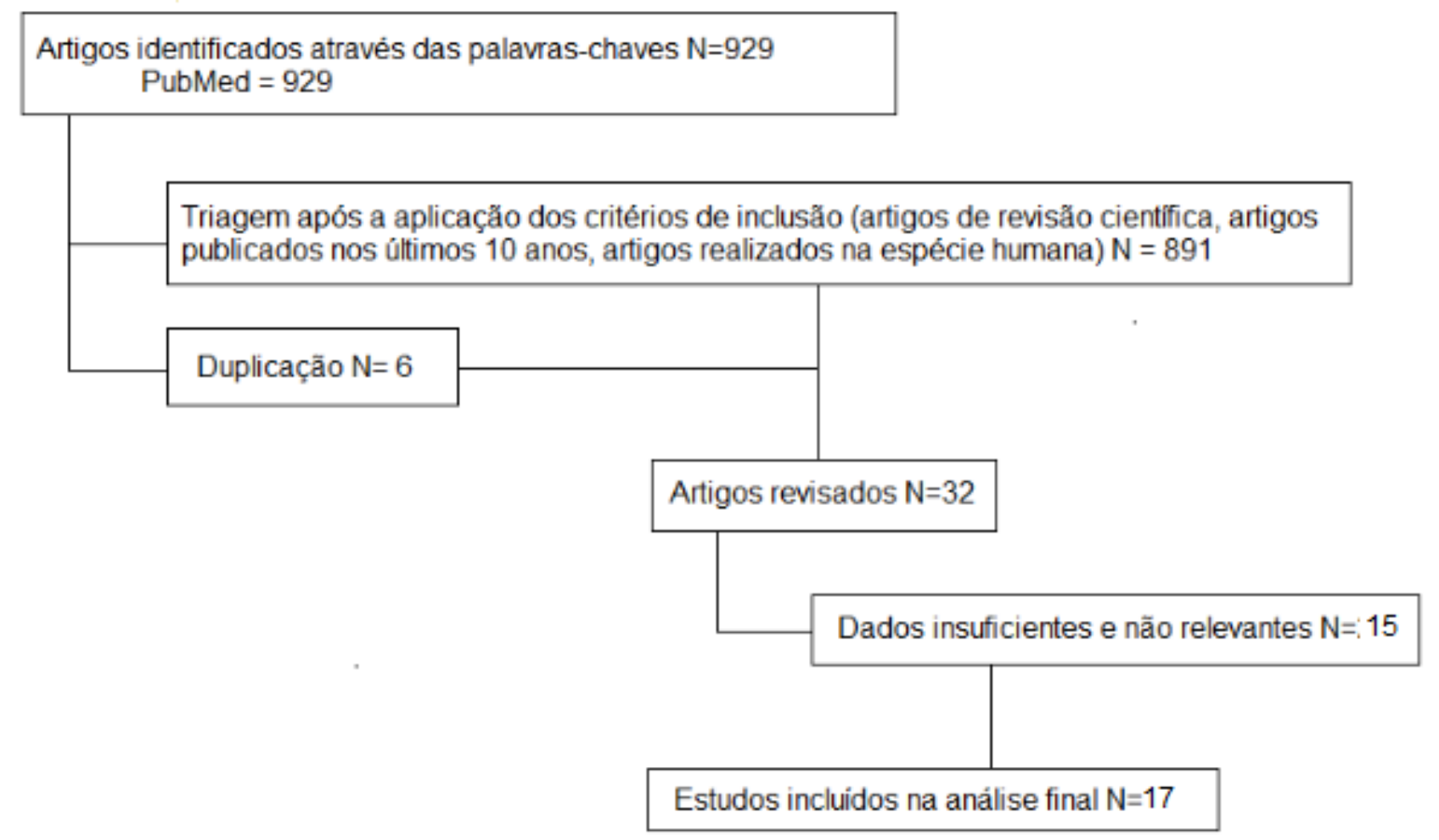

Fonte: Ladeia DN, et al., 2020. 
Quadro 1 - Tabela com os estudos encontrados na metodologia.

\begin{tabular}{|c|c|c|c|}
\hline Autor e ano & Objetivo do estudo & Base de dados & Resultados \\
\hline $\begin{array}{l}\text { Chrysostomou A, et } \\
\text { al. (2018) }\end{array}$ & $\begin{array}{l}\text { Avaliar criticamente os métodos atuais para } \\
\text { rastreamento do câncer de colo de útero }\end{array}$ & MEDLINE / PubMed & $\begin{array}{c}\text { A vacinação contra o HPV e a triagem cervical têm o potencial de } \\
\text { reduzir drasticamente a incidência e mortalidade do câncer } \\
\text { cervical }\end{array}$ \\
\hline Ding Y, et al. (2009) & $\begin{array}{l}\text { Avaliar a potencial aplicação do cogumelo } \\
\text { como adjuvante na imunoterapia tumoral }\end{array}$ & MEDLINE / PubMed & $\begin{array}{l}\text { A substância do cogumelo conferiu fortes efeitos antitumorais } \\
\text { profiláticos e terapêuticos }\end{array}$ \\
\hline $\begin{array}{l}\text { Domenico DF, et al. } \\
\qquad(2012)\end{array}$ & $\begin{array}{l}\text { Avaliar a capacidade dos polifenóis em } \\
\text { modular as vias moleculares envolvidas na } \\
\text { carcinogênese do HPV }\end{array}$ & MEDLINE / PubMed & $\begin{array}{l}\text { Os polifenois podem ser uma ferramenta terapêutica promissora } \\
\text { no tratamento do câncer de colo uterino }\end{array}$ \\
\hline Hu X, et al. (2017) & $\begin{array}{c}\text { Realizar uma meta-análise para verificar a } \\
\text { ação da vitamina } E \text { o risco de câncer } \\
\text { cervical. }\end{array}$ & MEDLINE / PubMed & A vitamina E pode reduzir a chance de câncer cervical. \\
\hline $\begin{array}{c}\text { Imran M, et al. } \\
(2017)\end{array}$ & $\begin{array}{c}\text { Avaliar o potencial da cúrcuma como } \\
\text { agente anticâncer }\end{array}$ & MEDLINE / PubMed & $\begin{array}{c}\text { A cúrcuma pode promover redução de tumores e diminuir a } \\
\text { progressão dos estágios de câncer cervical }\end{array}$ \\
\hline $\begin{array}{l}\text { Lopes VA, Ribeiro } \\
\text { JM (2019) }\end{array}$ & $\begin{array}{c}\text { Analisar os fatores limitantes e facilitadores } \\
\text { dos serviços de saúde públicos relacionado } \\
\text { ao câncer cervical }\end{array}$ & MEDLINE / PubMed & $\begin{array}{l}\text { São fatores facilitadores a cobertura mundial de Papanicolau. Já } \\
\text { a dificuldade de marcar consultas e exames são fatores } \\
\text { dificultadores }\end{array}$ \\
\hline $\begin{array}{l}\text { Oliveira MM, et al. } \\
\qquad(2013)\end{array}$ & $\begin{array}{l}\text { Descrever e estimar a cobertura do exame } \\
\text { preventivo no Brasil em mulheres entre } 25 \\
\text { e } 64 \text { anos. }\end{array}$ & MEDLINE / PubMed & $\begin{array}{c}\text { 89,4\% das mulheres brasileiras realizaram exame preventivo nos } \\
\text { últimos } 3 \text { anos. As mulheres de } 55 \text { a } 64 \text { anos e sem instrução } \\
\text { apresentam menores prevalências. }\end{array}$ \\
\hline Rauf A, et al. (2016) & $\begin{array}{c}\text { Discutir a ação do Resveratrol como agente } \\
\text { anti-câncer }\end{array}$ & MEDLINE / PubMed & $\begin{array}{l}\text { O Resveratrol tem capacidade de redução de diferentes tipos de } \\
\text { câncer, incluindo o cervical, pelo seu potencial anti-oxidante. }\end{array}$ \\
\hline HAN B, et al. (1999) & $\begin{array}{l}\text { Investigar se a apoptose induzida por } \\
\text { EDCB recruta caspases ou não. }\end{array}$ & MEDLINE / PubMed & $\begin{array}{l}\text { A atividade da caspase- } 3 \text { foi significativamente maior quando } \\
\text { tratada com ECBD e sua atividade doi nula com Z- VAD-FMK, um } \\
\text { conhecido inibidor de caspase- } 3 \text {. }\end{array}$ \\
\hline $\begin{array}{l}\text { Scorei RI, Popa R } \\
(2010)\end{array}$ & $\begin{array}{l}\text { Analisar dietas enriquecidas com Boro na } \\
\text { prevenção e tratamento de diversos tipos } \\
\text { de câncer. }\end{array}$ & MEDLINE / PubMed & $\begin{array}{l}\text { Dietas enriquecidas com boro apresentam redução significativa } \\
\text { em diversos tipos de câncer, como o câncer cervical. }\end{array}$ \\
\hline $\begin{array}{l}\text { MYUNG SK, et al. } \\
(2011)\end{array}$ & $\begin{array}{l}\text { Investigar por metanálise efeitos } \\
\text { quantitativos da ingestão vitaminas ou } \\
\text { antioxidantes na neoplasia cervical }\end{array}$ & MEDLINE / PubMed & $\begin{array}{l}\text { Efeitos preventivos significativos foram obtidos pela ingestão de } \\
\text { vitamina B12, vitamina E beta-caroteno. }\end{array}$ \\
\hline REN G, et al. (2008) & $\begin{array}{l}\text { Avaliar o mecanismo da apoptose-induzida } \\
\text { pela clitocina em células neoplásicas } \\
\text { cervicais. }\end{array}$ & MEDLINE / PubMed & $\begin{array}{c}\text { A indução da apoptose pela clitocina envolve múltiplas vias, como } \\
\text { a mitocondrial e a dos receptores da morte. }\end{array}$ \\
\hline $\begin{array}{l}\text { KYRGIOU M, et al. } \\
(2016)\end{array}$ & $\begin{array}{c}\text { Avaliar a relação entre microbiota vaginal e } \\
\text { aquisição e persistência da infecção pelo } \\
\text { vírus HPV. }\end{array}$ & MEDLINE / PubMed & $\begin{array}{c}\text { Os estudos atuais não apontam uma causalidade. Mais estudos } \\
\text { devem ser feitos para maior exploração de uma possível } \\
\text { causalidade. }\end{array}$ \\
\hline
\end{tabular}

REAS/EJCH | Vol.Sup.n.56 | e3923 | DOI: https://doi.org/10.25248/reas.e3923.2020 Página 4 de 10 
Revista Eletrônica Acervo Saúde / Electronic Journal Collection Health ～ISSN 2178-2091

\begin{tabular}{|c|c|c|c|}
\hline Autor e ano & Objetivo do estudo & Base de dados & Resultados \\
\hline $\begin{array}{l}\text { JUCKET G, } \\
\text { HARTMAN-ADAMS. } \\
\qquad(2010)\end{array}$ & $\begin{array}{l}\text { Discutir fatores de prevenção relacionados } \\
\text { ao câncer cervical. }\end{array}$ & MEDLINE / PubMed & $\begin{array}{l}\text { Uso de condom é apenas parcialmente protetor contra a infecção } \\
\text { por papiloma vírus humano. As duas vacinas humanas contra o } \\
\text { vírus HPV são mais eficazes quando administradas em pacientes } \\
\text { do sexo feminina que não iniciaram atividades sexuais. }\end{array}$ \\
\hline $\begin{array}{l}\text { Wang YQ, et al. } \\
(2018)\end{array}$ & $\begin{array}{l}\text { Discutir os efeitos supressivos do EGCG no } \\
\text { câncer cervical. }\end{array}$ & MEDLINE / PubMed & $\begin{array}{l}\text { O EGCG tem habilidade anti-proliferativa, anti-mestastática e pró- } \\
\text { apoptose no câncer cervical. }\end{array}$ \\
\hline $\begin{array}{l}\text { Zhang S, Batur P } \\
\qquad(2019)\end{array}$ & $\begin{array}{l}\text { Atualização das formas de prevenção e } \\
\text { rastreamento do câncer cervical }\end{array}$ & MEDLINE / PubMed & $\begin{array}{c}\text { Os profissionais de saúde podem ajudar a prevenir o câncer } \\
\text { cervical recomendando a vacina de HPV quando apropriado, } \\
\text { realizar o rastreamento de câncer cervical e acompanhamento } \\
\text { dos testes anormais }\end{array}$ \\
\hline $\begin{array}{l}\text { Silva GA, et al. } \\
\qquad(2018)\end{array}$ & $\begin{array}{l}\text { Demonstrar como o uso de antioxidantes } \\
\text { pode prevenir o câncer cervical }\end{array}$ & MEDLINE/ PubMed & $\begin{array}{l}\text { O uso de antioxidantes naturais como vitamina } \mathrm{B} 6 \text {, vitamina } \mathrm{C} \text {, } \\
\text { cúrcuma, resveratrol podem atuar como alternativas na } \\
\text { prevenção pois agem evitando que o estresse oxidativo atue em } \\
\text { conjunto com o vírus HPV. }\end{array}$ \\
\hline $\begin{array}{l}\text { Vonsky MS, et al. } \\
\qquad(2019)\end{array}$ & $\begin{array}{l}\text { Discussão do vírus HPV, dos mecanismos } \\
\text { de replicação viral, formas de HPV e } \\
\text { mecanismos moleculares da carcinogênese. } \\
\text { Além de demonstrar a prevalência e a } \\
\text { evolução clínica dos tipos de HPV e dos } \\
\text { cânceres associados a infecção pelo vírus e } \\
\text { a forma de atuação da vacina profilática. }\end{array}$ & MEDLINE/ Pubmed & $\begin{array}{l}\text { A vacinação profilática apresenta diversas possibilidades de } \\
\text { auxiliar a impedir o desenvolvimento do câncer. A vacina deve ser } \\
\text { administrada no início da adolescência, antes da infecção pelo } \\
\text { HPV, uma vez que a vacinação tardia não tem efeito na } \\
\text { persistência do HPV em indivíduos já infectados. }\end{array}$ \\
\hline $\begin{array}{l}\text { Vonsky MS et al. } \\
\qquad(2019)\end{array}$ & $\begin{array}{c}\text { Discussão sobre a carcinogênese } \\
\text { provocada pelo HPV e descrever a atuação } \\
\text { e necessidade de criação de vacinas } \\
\text { terapêuticas que provoquem a resposta } \\
\text { imune capaz de eliminar as células } \\
\text { infectadas e malignas que expressam } \\
\text { proteínas virais. }\end{array}$ & MEDLINE/ Pubmed & $\begin{array}{c}\text { Até o momento, mesmo atuando com imunoterapeuticos, vacinas } \\
\text { já testadas e combinação com imunomodeladores, nenhuma } \\
\text { vacina foi capaz fornecer regressão completa do HPV associado a } \\
\text { malignidades. }\end{array}$ \\
\hline $\begin{array}{l}\text { SUN-DONG Z, et al. } \\
(2019)\end{array}$ & $\begin{array}{l}\text { Avaliar como o fungo medicinal Inonotus } \\
\text { obliquus (cogumelo chaga) pode apresentar } \\
\text { potencial mecanismo molecular antitumoral. }\end{array}$ & MEDLINE/ Pubmed & $\begin{array}{c}\text { O inotodiol inibiu significativamente a migração e invasão de } \\
\text { células tumorais de maneira dose-dependente, além de induzir } \\
\text { apoptose de alguns oncogênes em ensaios clínicos. No entanto, } \\
\text { algum desse efeito de inibição foi bloqueado por proteínas (p53) } \\
\text { presentes nas células tumorais. }\end{array}$ \\
\hline
\end{tabular}

Fonte: Ladeia DN, et al., 2020.

REAS/EJCH | Vol.Sup.n.56 | e3923 | DOI: https://doi.org/10.25248/reas.e3923.2020 Página $\mathbf{5}$ de 10 
Lopes VAS e Ribeiro JM (2018), Oliveira MM, et al. (2018), e Chrysostomou A, et al. (2018) explanaram a respeito da importância da cobertura do exame de Papanicolau e do tratamento dentro do período adequado. Os 3 autores mostraram que o exame de triagem é essencial para a detecção precoce e cura do câncer do colo de útero. Porém, fatores socioeconômicos, culturais e demográficos que permeiam essas mulheres são um entrave para a ação.

Ainda que alguns artigos incluídos na análise final, explicitem que o uso de antioxidantes como fator protetor do câncer de colo de útero necessitam de estudos mais aprofundados, os autores relataram em seus estudos a efetividade do uso de antioxidantes como potencial atividade preventiva (HU X, et al., 2017; DOMENICO DF, et al., 2012; SILVA GA, et al., 2018; RAUF A, et al., 2017; IMRAN M, et al., 2017; SCOREI RI e POPA R, 2010 e MYUNG SK, et al., 2011).

O cogumelo Chaga (Inonotus obliquus), através do estudo de Sun-Dong Z, et al. (2019), mostrou-se também como uma potencial alternativa natural na prevenção da instalação do tumor e da apoptose de células tumorais, uma vez que esses cogumelos obtiveram efetividade contra a migração e invasão das células afetadas pelo câncer cervical.

Alguns autores relataram a importância da vacinação profilática para a redução dos casos de HPV em mulheres (CHRYSOSTOMOU A, et al., 2018; ZHANG S e BATUR P, 2019; VONSKY M, et al., 2019; JUCKETT G e HARTMAN-ADAMS H 2010; WANG YQ, et al., 2018). Além disso, Juckett G e Hartman-Adams $\mathrm{H}$, (2010) indicam a importância da vacinação em homens, porém mais estudos seriam necessários para comprovar a eficácia nessa diminuição.

Assim como o uso de preservativos como parcialmente protetores na infecção pelo HPV e a circuncisão, que também reduz a chance de o homem contrair o HPV e, consequentemente, transmiti-lo para suas parceiras. Vonsky M, et al. (2019) e Vonsky MS, et al. (2019), indicaram a necessidade da criação de uma vacina terapêutica para atuação no câncer cervical já em desenvolvimento, uma vez que a vacina profilática não atua no processo do câncer já em evolução.

Através dos artigos selecionados na análise final, além do exame de Papanicolau, uso de antioxidantes, vacinação profilática, preservativos, circuncisão e uso de cogumelos, foi identificado no estudo de Kyrgiou M, et al. (2016) que a microbiota vaginal é também um fator de proteção para o câncer cervical, ainda que estudos subsequentes sejam necessários para determinar o tipo de preparação mais eficaz e protetora. Sendo assim, a análise dos 12 artigos selecionados na plataforma PubMed explicitou a significância dos diversos fatores de proteção para o câncer de colo de útero.

\section{DISCUSSÃO}

\section{Citopatológico do Colo de Útero ou Papanicolau}

O exame citopatológico do colo uterino ou Papanicolau, apesar de ser uma forma de rastreamento para diagnóstico precoce de câncer cervical, é um importante mecanismo de proteção na medida que identifica lesões precursoras dessa neoplasia.

Segundo Oliveira MM, et al. (2018), o Papanicolau é um exame seguro e simples, sendo no Brasil amplamente ofertado nas Unidades Básicas de Saúde. Ainda de acordo com Oliveira MM, et al. (2018), o exame deve ser realizado em mulheres entre 25 a 64 anos de idade que iniciaram relações sexuais e deve ser realizado de 3 em 3 anos em caso de 2 resultados negativos. Zhang $S$ e Batur $P(2019)$ estipulam que o rastreamento deve ser iniciado aos 21 anos e terminado aos 65 anos, independente do estado vacinal e da iniciação sexual.

Além disso, mulheres infectadas pelo vírus da imunodeficiência humana podem realizar testes a cada três anos, após três resultados anuais consecutivos normais, e pacientes imunossuprimidos ou com histórico de exposição ao dietilestibestrol devem realizar exames anualmente (ZHANG S e BATUR P, 2019).

No Brasil, o exame grande relevância, uma vez que o diagnóstico das alterações precursoras como neoplasias e displasias em estágio inicial, possui potencial de cura de até 100\% (OLIVEIRA MM, et al., 2018). Essa informação é corroborada pela redução em mais de $60 \%$ da incidência de câncer de colo uterino nos Estados Unidos após a introdução do exame citopatológico do colo do útero como método de rastreamento populacional (ZHANG S e BATUR P, 2019). 
Entretanto, segundo Lopes VAS e Ribeiro JM (2018), a triagem do câncer cervical é influenciada por barreiras organizacionais, sociais, econômicas, culturais e raciais, o que pode dificultar a eficácia dessa ação. Dessa forma, ainda há altas taxas de não realização do exame Papanicolau e um grande número de casos em estadiamento avançado, reforçando a importância de sua realização (LOPES VAS e RIBEIRO JM, 2018). Além disso, tanto Oliveira MM, et al. (2018) quanto Zhang S e Batur P (2019), acreditam ser imprescindível o acompanhamento dos resultados anormais do exame de rastreamento na promoção da saúde.

Como instrumento eficaz, de acordo com Chrysostomou A, et al. (2018), o teste de DNA do HPV, com foco nos tipos de alto risco, tem sido considerado mais sensível que o rastreamento de Papanicolau, apesar da sua especificidade ser inferior à da citologia. Como forma de melhorar a acurácia da detecção, o rastreamento com testes de DNA do HPV, em combinação com a citologia, se mostra eficaz no diagnóstico precoce da infecção pelo HPV, protegendo, assim, as mulheres contra o desenvolvimento do câncer do colo de útero.

Além disso, conforme Juckett G, et al. (2010), o teste de captura híbrida de HPV de alto risco, técnica mais frequentemente usada com fins de detectar DNA-HPV, tem um alto valor preditivo negativo, porém somente categoriza os tipos de HPV em dois grupos (alto e baixo risco), não identificando o tipo específico isoladamente. Em pacientes submetidas à exérese de lesões cervicais de alto grau, o elevado valor preditivo negativo do teste DNA-HPV é um importante critério de cura e prognóstico, visto que pacientes com colpocitologia normal e teste de DNA-HPV de alto risco negativo apresentam baixa possibilidade de desenvolver ou recidivar lesão de alto grau, podendo retornar à rotina citológica de rastreio anual ou trianual (JUCKETT G, et al., 2010).

\section{Vacinação}

As vacinas de HPV são fundamentais para a proteção contra o câncer cervical e, segundo Wang YQ, et al. (2018), é o método mais eficaz para a prevenção para esse tipo de câncer, sendo que no Brasil, a vacina disponível no Sistema Único de Saúde é a quadrivalente.

De acordo com Zhang S e Batur P (2019), existem 3 tipos de vacina sendo a bivalente direcionada para as cepas 16 de 18 de HPV, as quais possuem maior potencial carcinogênico e a quadrivalente, também conhecida como Gardasil, direcionada para os tipos 16, 18, 6 e 11. Além disso, a vacina disponível nos Estados Unidos é a Gardasil 9, que além da prevenção dos tipo 16, 18, 6 e 11, também promove proteção das cepas 31, 33, 45, 52 e 58, considerando que esses 9 tipos de HPV são responsáveis por $90 \%$ dos cânceres de colo uterino e grande parte das verrugas genitais causadas por esse vírus (LOPES VAS e RIBEIRO JM, 2018; ZHANG S e BATUR P, 2019).

Ademais, é importante ressaltar que, segundo Vonsky M, et al. (2019), a vacina oferece $98 \%$ de proteção contra infecções pelos tipos de HPV citados anteriormente, reduzindo drasticamente o risco de carcinoma cervical escamoso, adenocarcinomas e outras complicações causadas pela infecção do HPV. Portanto, é fundamental que os médicos e outros profissionais de saúde expliquem e recomendem para as famílias a vacinação contra o HPV, uma vez que estudos têm mostrado que esse tipo de abordagem aumenta 9 vezes mais a adesão a primeira dose da vacina (ZHANG S e BATUR P, 2019).

\section{Imunoterapia com cogumelos}

A imunoterapia específica com metabólitos extraídos de cogumelos é uma estratégia promissora para erradicar tumores (DING Y, et al., 2009). Os achados de Ding Y, et al. (2009) sobre a proteção tumoral in vivo mostraram que $60 \%$ dos camundongos co-imunizados com HPV-16 E7 juntamente com Fve permaneceram livres de tumor, em comparação com apenas 20\% dos camundongos imunizados apenas com HPV-16 E7.

Os achados de Han B, et al. (1999) mostram que a atividade da caspase-3 na via de apoptose aumentou notavelmente quando a célula foi tratada com EDCB, e essa atividade foi anulada por um inibidor da caspase3. Estudos in vitro de Ren G, et al. (2008) demonstraram que a clitocina do cogumelo poderia inibir a proliferação de células de carcinoma do colo do útero humano pelo mecanismo envolvido na indução de apoptose.

Por último, se tratando de estudos acerca da farmacologia dos cogumelos, os achados de Zhang SD, et al. (2019) mostraram que o ensaio de viabilidade celular mostrou que a baixa concentração de Inotodiol não apresentava citotoxicidade para as células de carcinoma do colo do útero humano e que a concentração 
acima de $25 \mu \mathrm{M}$ inibiu significativamente o crescimento celular e induziu apoptose. Assim, vemos a importância e a necessidade de mais pesquisas acerca do potencial farmacológico de subprodutos de diversas espécies de cogumelos. Esta pode ser uma via alternativa e promissora para futuros tratamentos do câncer de colo de útero humano.

\section{Agentes antioxidantes}

Sobre a infecção persistente por vários tipos de papilomavírus humano de alto risco, Silva GA, et al. (2018) sugere uma associação entre respostas inflamatórias e produção reativa de espécies de oxigênio. Nesse contexto, o estresse oxidativo, a inflamação crônica e o HPV de alto risco podem atuar de maneira sinérgica na carcinogênese, sendo, portanto, o uso de substâncias antioxidantes um interessante fator de proteção contra o desenvolvimento do câncer de colo de útero. Considerando essa abordagem, alguns estudos apontaram a Vitamina E, um importante antioxidante, como fator protetivo para a neoplasia em questão.

De acordo com Hu X, et al. (2017), essa substância protege as células cervicais dos danos oxidativos que levam a lesões precursoras e posteriormente ao câncer. Apesar dos seus mecanismos de ação não serem totalmente esclarecidos, sabe-se que esse antioxidante evita danos ao material genético pela eliminação dos radicais lipídicos e peróxido de hidrogênio impedindo a peroxidação lipídica e consequentemente as mutações dos genomas da região (HU X, et al., 2017).

Seguindo esta mesma linha de efeitos protetores, foi demonstrada, na meta-análise de estudos de casocontrole de Myung SK, et al. (2011), uma significativa associação entre a maior ingestão ou nível sérico de vitamina B12, vitamina C, vitamina E e licopeno com a diminuição do risco de neoplasia intraepitelial cervical, em comparação com a menor ingestão ou nível sérico. Enquanto isso, nenhuma associação foi observada para vitamina $A$, betacaroteno, folato e selênio.

Esse desfecho é corroborado pelo estudo de Silva GA, et al. (2018), o qual aponta que suplementações alimentares com as vitaminas $\mathrm{C}$ e B6 podem reduzir o risco de NIC em mulheres com infecção por HPV de alto risco, sendo uma alternativa viável contra o avanço das lesões precursoras do câncer cervical. Entretanto, na pesquisa de Myung SK, et al. (2011), não foi possível avaliar a relação dose-resposta entre a ingestão de vitaminas ou antioxidantes e o risco de neoplasia cervical, já que foram utilizadas apenas as categorias extremas, maior ou menor consumo ou nível sérico, salientando a necessidade de pesquisas futuras sobre 0 tema.

Outro promissor antioxidante que vem sendo estudado é o Resveratrol, encontrado em uvas vermelhas, amendoins e outras fontes alimentícias. Tal substância, conforme Rauf A, et al. (2017) e Silva GA, et al. (2018), possui efeito protetor contra diversos tipos de câncer, incluindo o câncer cervical, por possuir ação na inflamação e na carcinogênese. Os mecanismos de ação do Resveratrol ainda estão sendo identificados, mas, segundo Rauf A, et al. (2017), alguns já podem ser explicados.

Os seus principais efeitos são apoptose celular, ação anti-inflamatória e antiproliferativa. Dessa forma, um de seus mecanismos é a melhora da permeabilidade lisossômica e a diminuição da expressão de P53 e P65, o que induz a morte celular nas células acometidas por alterações neoplásicas. Além disso, essa substância inibe a COX e aumenta a presença de marcadores utilizados por autofagossomos (RAUF A, et al., 2017).

Ademais, de acordo com Silva GA, et al. (2018), a Epigalocatequina-3-galato, encontrada no chá verde, é uma substância antioxidante utilizada como fator de proteção ao desenvolvimento do câncer cervical. Esse composto apresenta efeitos antiproliferativos, antiangiogênicos, antimetastáticos e pró-apoptóticos em vários modelos de tumores. Além de direcionar o crescimento celular e a apoptose, esse potente antioxidante pode inibir ainda mais a ação da telomerase, prejudicando o início e o desenvolvimento de lesões cervicais.

A cúrcuma é um componente natural do açafrão com ação antioxidante que possui capacidade de impedir a progressão de neoplasias de estágios mais avançados, uma vez que bloqueia enzimas necessárias ao crescimento de tumores (IMRAN M, et al., 2017). Tal substância atua na atividade do óxido nítrico, proteína C quinase e alguns fatores de crescimento. Além disso, de acordo com Imran M, et al. (2017), estudos demonstram que a cúrcuma possui capacidade antitumoral nas células ligadas ao HPV e papel antiproliferativo contra diversos linhas celulares do câncer cervical, podendo induzir a apoptose. 


\section{Dietas ricas em Boro}

Ademais, existem estudos a respeito do papel em dietas ricas em Boro na redução do risco de diversos tipos câncer, incluindo o câncer de colo de útero. Segundo Scorei RI e Popa R (2010) a menor incidência de câncer cervical na Turquia, o qual ocupa o sétimo lugar nos cânceres mais frequentes em mulheres, pode estar relacionado com o solo enriquecido com o Boro, o que leva a sua maior ingestão pela água. Essa substância pode interferir com o ciclo celular do HPV, apesar de que a relação não foi encontrada nos cânceres bucais induzidos pelo HPV. Dessa forma, o boro tem capacidade de reduzir a imortalidade, transformação do oncogene, além da capacidade invasiva das células cancerígenas (SCOREI RI e POPA R, 2010).

\section{Microbiota vaginal}

De acordo com Kyrgiou M, et al. (2016), evidências indicam que a microbiota vaginal, quando em equilíbrio, pode desempenhar um papel protetor na aquisição e persistência do HPV e no subsequente desenvolvimento do câncer de colo uterino. As comunidades bacterianas vaginais saudáveis, em mulheres na menacme, são habitualmente preenchidas por Lactobacillus ssp., comumente considerados para garantir um pH baixo e fornecer a primeira linha de defesa contra agentes patogênicos. Alguns tipos de Lactobacillus spp., principalmente $o L$. crispatus, fornecem muitas substâncias protetoras, as quais podem ser relevantes para 0 HPV. Em contraste, o L. iners parece mais comumente associado à doença do que à saúde, ressaltando que nem todos os Lactobacillus são igualmente protetores (KYRGIOU M, et al., 2016).

Nas meta-análises de estudos transversais apresentadas por Kyrgiou M, et al. (2016), a presença de um desequilíbrio da microbiota vaginal, como ocorre na vaginose bacteriana, foi associada a perfis próinflamatórios e taxas mais altas de infecção pelas cepas oncogênicas do HPV, sugerindo que uma microbiota diversificada e com falta de Lactobacillus pode contribuir para a persistência do HPV e consequentemente para um maior risco de câncer cervical. Corroborando com essa evidência, estudos também demonstrados por Kyrgiou M, et al. (2016) que descrevem a microbiota vaginal em mulheres com doença pré-invasiva (neoplasia intraepitelial cervical) demonstram consistentemente um desequilíbrio na flora nos casos com a doença mais grave.

\section{CONSIDERAÇÕES FINAIS}

Considerando a importância epidemiológica do câncer de colo de útero, é de grande relevância a busca por dados que levem à fatores protetores desta neoplasia. A vacina preventiva contra o HPV foi considerada o método mais eficaz para a proteção contra o câncer cervical. O exame citopatológico do colo uterino aparece como importante rastreio para diagnóstico precoce da infecção pelo vírus HPV que pode evitar seu desenvolvimento e o desfecho negativo. A microbiota vaginal em equilíbrio foi apontada como um protetor na aquisição e desenvolvimento do vírus HPV. Ainda, agentes antioxidantes, assim como o uso de cogumelos comestíveis, se mostraram alternativas viáveis na proteção, mesmo que careçam de mais estudos elucidativos.

\section{REFERÊNCIAS}

1. CHRYSOSTOMOU A, et al. Cervical Cancer Screening Programs in Europe: The Transition Towards HPV Vaccination and Population-Based HPV Testing. Viruses, 2018; 10: 729.

2. DING Y, et al. Coadministration of the fungal immunomodulatory protein FIP-Fve and a tumour-associated antigen enhanced antitumour immunity. Blackwell Publishing Ltd, Immunology, 2009; 128: e881-e894.

3. DOMENICO DF, et al. Antioxidants in cervical cancer: Chemopreventive and chemotherapeutic effects of polyphenols. Biochimica et Biophysica Acta, 2012; 1822: 737-747.

4. HAN B, et al. Induction of Apoptosis by Coprinus disseminatus Mycelial Culture Broth Extract in Human Cervical Carcinoma Cells. Cell Struture And Function, 1999; 24: 209-215.

5. HU X, et al. Effect of vitamin E supplementation on uterine cervical neoplasm: A meta-analysis of case-control studies. PLoS ONE, 2017; 12(8): e0183395.

6. IMRAN M, et al. Cucurmin, anticancer, \& antitumor perspectives: A comprehensive review. Critical Reviews in Food Science and Nutrition, 2017; 58: 1271- 1293.

7. JUCKET G, HARTMAN-ADAMS. Human Papillomavirus: Clinical Manifestations and Prevention. American Family Physician, 2010; 82(10): 1209-1214.

8. KYRGIOU M, et al. Does the vaginal microbiota play a role in the development of cervical cancer?. Elsevier, 2016; 179: 168-182. 
9. LOPES VA, RIBEIRO JM. Cervical cancer control limiting factors and facilitators: a literature review. Ciência e Saúde Coletiva, 2019; 24(9): 3431-3442.

10. MYUNG SK, et al. Vitamin or antioxidant intake (or serum level) and risk of cervical neoplasm: a meta-analysis. BJOG, 2011; 118: 1285-1291.

11. OLIVEIRA MM, et al. Pap-test coverage in women aged 25 to 64 years old, according to the National Health Survey and the Surveillance System for Risk and Protective Factors for Chronic Diseases by Telephone Survey, 2013. Rev Bras Epidemiol 2018; 21: E180014.

12. RAUF A, et al. Resveratrol as an Anticancer Agent: A Review. Phytomedicine 2016; 23(5): 566-577.

13. REN G, et al. Anti-proliferative effect of clitocine from the mushroom Leucopaxillus giganteus on human cervical cancer HeLa cells by inducing apoptosis. Cancer Letters, 2008; 262: 190-200.

14. SCOREI RI, POPA R. Boron-Containing Compounds as Preventive and Chemotherapeutic Agents for Cancer. AntiCancer Agents in Medicinal Chemistry, 2010; 10: 346-351.

15. SILVA GA, et al. Oxidative stress: therapeutic approaches for cervical cancer treatment. CLINICS, 2018; 73(suppl 1): e548s.

16. SUN-DONG Z, et al. Inotodiol inhibits cells migration and invasion and induces apoptosis via p53-dependent pathway in HeLa cells. Phytomedicine, 2019; 60: 152957.

17. VONSKY M, et al. Carcinogenesis Associated with Human Papillomavirus Infection. Mechanisms and Potential for Immunotherapy. Biochemistry (Moscow), 2019; 84 (7): 782-799.

18. VONSKY MS, et al. Therapeutic Vaccines Against Human Papilloma Viruses: Achievements and Prospects. Published in Russian in Biokhimiya, 2019; 84 (7): 1016-1035.

19. WANG YQ, et al. Suppressive Effects of EGCG on Cervical Cancer. Molecules, 2018; 23: 2334.

20. ZHANG S, BATUR P. Human papillomavirus in 2019: An update on cervical cancer prevention and screening guidelines. Cleveland Clinic Journal of Medicine, 2019; 86(3). 